\title{
LICENSING LIFE-SAVING DRUGS FOR DEVELOPING COUNTRIES: EVIDENCE FROM THE MEDICINES PATENT POOL
}

\author{
Alberto Galasso \\ Mark Schankerman \\ Working Paper 28545 \\ http://www.nber.org/papers/w28545 \\ NATIONAL BUREAU OF ECONOMIC RESEARCH \\ 1050 Massachusetts Avenue \\ Cambridge, MA 02138 \\ March 2021
}

We thank Esteban Burrone and Amina Maillard for providing access to licensing data and for helpful discussions about the Medicine Patent Pool. We are grateful to Saul Lach, William Matcham, Tim Simcoe and seminar participants at the University of Toronto for helpful comments. Harveen Sidhu provided excellent research assistance. We are grateful for financial support from the Social Sciences and Humanities Research Council of Canada. The views expressed herein are those of the authors and do not necessarily reflect the views of the National Bureau of Economic Research.

NBER working papers are circulated for discussion and comment purposes. They have not been peer-reviewed or been subject to the review by the NBER Board of Directors that accompanies official NBER publications.

(C) 2021 by Alberto Galasso and Mark Schankerman. All rights reserved. Short sections of text, not to exceed two paragraphs, may be quoted without explicit permission provided that full credit, including $\odot$ notice, is given to the source. 
Licensing Life-Saving Drugs for Developing Countries: Evidence from the Medicines Patent Pool

Alberto Galasso and Mark Schankerman

NBER Working Paper No. 28545

March 2021

JEL No. I18,O31,O34

\begin{abstract}
We study the effects of an institution that pools patents across geographical markets on the licensing and adoption of life-saving drugs in low- and middle-income countries. Using data on licensing and sales for HIV, hepatitis C and tuberculosis drugs, we show that there is an immediate and large increase in licensing by generic firms when a patent is included in the Medicines Patent Pool (MPP). The effect is heterogeneous across countries. The findings are robust to identification strategies to deal with endogeneity of MPP patents and countries. The impact on actual entry and sales, however, is much smaller than on licensing, which is due to geographic bundling of licenses by the MPP. More broadly, the paper highlights the potential of pools in promoting technology diffusion in developing countries.
\end{abstract}

\author{
Alberto Galasso \\ Rotman School of Management \\ University of Toronto \\ 105 St. George Street \\ Toronto, ON M5S 3E6 \\ CANADA \\ and NBER \\ alberto.galasso@rotman.utoronto.ca \\ Mark Schankerman \\ Department of Economics, R.516 \\ London School of Economics \\ Houghton Street \\ London WC2A 2AE \\ UK \\ M.Schankerman@1se.ac.uk
}




\section{Introduction}

In 2008 the U.S. Food and Drug Administration approved the use of Etravirine, an HIV antiretroviral drug designed for patients with established resistance to other drugs. Yet, by 2015, Etravirine was available only in about 25 percent of the lower and upper middle-income countries in Central and Eastern Europe. This is not atypical - other important HIV antiretrovirals and drug cocktails, all of them on the Essential Drug List of the World Health Organisation (WHO), have limited availability in these countries (Gokengin et al., 2018). Nor are such delays limited to HIV drugs. Cockburn, Lanjouw and Schankerman (2016) show that global drug diffusion is very slow, especially in countries with relatively low income.

Promoting rapid and affordable access to essential drugs is a key health policy objective. One proposed approach is to use patent pools, which are voluntary arrangements where patentees authorize the pool to license specific patents, typically as a bundle, to third parties. Historically, patent pools have been widely used in conjunction with technology standards e.g., in the electronic and information technology sectors - where the focus is on licensing complementary innovations. Such pools are designed to facilitate commercialisation of standardcompliant products and follow-on innovation by lowering the transaction costs of licensing and coordinating the use of complementary innovations (Merges 2001). More recently, a different type of patent pool has been proposed in the biomedical field, which focuses on promoting wider geographic diffusion of specific innovations rather than aggregating technologically-related innovations. Examples include vaccines for the SARS epidemic, neglected tropical diseases and diagnostic testing (Van Zimmeren et al., 2011), and the COVID-19 patent pool recently proposed by the WHO. ${ }^{1}$

Advocates of geographic patent pools argue that they can be particularly beneficial for promoting the diffusion of essential pharmaceutical products in small, low- and middle-income countries, where market entry may be at best marginally profitable. A specialized, centralized licensing platform may reduce the transaction costs of writing, monitoring and enforcing patent contracts between drug companies and generic manufactures, and thereby facilitate product launches in poor countries. However, skeptics claim that these pools are essentially public relations exercises, and that there is no evidence of real impact on access to medicines (Kennedy, 2015). They also argue that pharmaceutical companies can unilaterally facilitate diffusion

\footnotetext{
${ }^{1}$ For further discussion of this, and other policy options, see Gans (2020).
} 
in low-income countries by not filing, or committing not to enforce, patents in those markets. Other critics point out that the Trade-Related Aspects of Intellectual Property Rights (TRIPS) agreement allows countries to facilitate access by generic manufacturers through flexible provisions, such as compulsory licensing. These different views in the policy debate highlight the need for empirical research.

There is very limited evidence on whether patent pools do, in practice, promote licensing and product launches. For this purpose, one needs licensing information not only for pool patents but also for a control group of patents before and after pool formation. This is typically difficult to obtain given the confidentiality of licensing contracts. In this paper, we exploit a rich dataset on licensing from the Medicines Patent Pool (MPP) that allows us to conduct such empirical analysis. Established by the United Nations in 2010, the MPP is a voluntary licensing institution with a mandate to promote access to affordable and quality-assured treatments for HIV, tuberculosis and hepatitis-C in low- and middle-income countries. The MPP negotiates inclusion of patents in the pool with patent-holding pharmaceutical companies, and then licenses the patent rights to interested generic drug companies. MPP licenses are non-exclusive, with low or zero royalty rates, and wide geographical scope. Since the MPP typically targets markets that are likely to be of limited profitability for patent-holding pharmaceutical companies, the decision to allow products to enter the MPP, covering an agreed set of countries, is often driven by corporate social responsibility objectives.

We study how the Medicines Patent Pool affects the licensing, launch and sales of drugs in low- and middle-income countries. We begin with a simple model that compares licensing and launch outcomes under two alternative arrangements, bilateral licensing by the patentee and a pool with geographical bundling. The model generates two main results. First, a patent pool with bundled licensing has an ambiguous effect on the amount of licensing. In the absence of the pool, the potential licensee bargains bilaterally with the upstream patentholder over the patents it intends to commercialize, and launches a drug in a given country if the profits from doing so exceed the licensing and entry costs. In the presence of a pool, the potential licensee faces lower transactions costs of licensing a patent for a given country, but is constrained to license the patent in all the countries designated by the pool. Thus the geographic bundling may increase total transaction costs and make it unprofitable for the licensee to license the bundle, when it would have been profitable to license the patent for a restricted set of countries. In this case, the pool induces less overall licensing than bilateral licensing arrangements. Second, 
the model shows that mandatory bundled licensing by the pool reduces the correlation between licensing and drug launch. This occurs because the firm is constrained to license a bundle of patents which may include those covering markets for which a launch is unprofitable.

Our empirical analysis is based on panel data covering 173 pharmaceutical products and 129 countries over the period 2005-2018. The product set encompasses medicines for HIV, tuberculosis and hepatitis- $\mathrm{C}$ recognized as essential by the WHO. The countries in our sample are those classified by the World Bank as low- or middle-income and for which patent protection was in place for at least one of the sample drugs. We obtain licensing information for each product-country from the MPP. Crucially, the licensing information includes both MPP licenses and non-MPP bilateral licenses between the upstream patentee and generic firms, and covers both the medicines in the pool and other products in our sample. Moreover, licensing data are available from 2005, five years before the formation of the pool.

Using difference-in-differences as the baseline specification, we show that the likelihood of observing patent licensing deals covering a product-country combination increases substantially once the patents related to the product-country dyad are included in the MPP. The probability of having at least one license to a generic firm increases more than five-fold relative to nonMPP product-countries. This finding is robust to a wide variety of alternative specifications and controls.

There are two key endogeneity concerns with the baseline specification. The first relates to the selection of which products enter into the MPP through upstream negotiations between the patentholder and the MPP. There may be unobservable factors that are correlated with the inclusion of a medicine in the MPP and which also affect diffusion of the product across countries. For example, the MPP may be interested in the most effective drugs which, in turn, would also be more attractive to generic licensees. The second endogeneity concern relates to the geographical coverage of a given product in the MPP, which is determined by negotiations with the upstream patentholder. Again, unobservable features of the product-country dyad may make inclusion in the MPP less likely and, at the same time, a launch more likely. For example, the patentholder may be more likely to strike a non-MPP bilateral deal with an exclusive licensee when a geographic market is more attractive for whatever reason. While we control for demographic characteristics in the empirical analysis, we cannot control for other unobservable factors.

We use two identification strategies to address these concerns. To address endogeneity of 
MPP products, we exploit the list of medicines that the MPP aimed to license when the pool was formed in 2010. This list includes about 80 products. Fewer than half of these medicines eventually made it in the pool, but the MPP started a negotiation with the relevant patentees for all of them. This information allows us to estimate the effect of inclusion in the MPP using as the control group those drugs for which bargaining with the pool started but failed. This identification strategy is closely related to the approach in Greenstone et al. (2010), who estimate the effect of large plant openings in a county using as a counterfactual counties that were considered by the plant managers but not chosen. We show that the estimates of the impact of the MPP using this approach are quantitatively similar to our baseline estimates.

We address the endogeneity of country coverage in MPP licenses as follows. Discussions with MPP executives, and official publications, confirm that the MPP focus on countries classified by the World Bank as low- and lower middle-income in their negotiations with upstream drug companies. The main reason is that upper middle-income countries are seen by pharmaceutical companies as large commercial markets (such as Brazil and China), so this entire set of countries often is not considered in the bargaining. Consistent with this, we find a large discontinuity in the likelihood of inclusion in the MPP for countries marginally above the upper middle-income threshold relative to those marginally below it as measured in the year the drug entered the MPP. Building on this result, we exploit the quasi-exogenous variations in country incomes in the neighborhood of the upper middle-income cut-off as an instrument in a fuzzy regression discontinuity design. We show that our results with this identification strategy are similar to those from our baseline specification.

There are three key empirical findings. First, inclusion in the pool is associated with a five-fold increase in the probability of licensing, as discussed above. Second, the effect is heterogeneous: we show that the increase in licensing due to the MPP is much larger for small, non-sub-Saharan countries, and smaller in countries with large exposure to HIV. Large countries with high HIV incidence are more attractive markets for pharmaceutical companies, and bilateral deals are more likely to have been in place before the MPP. Thus, we expect that joining the MPP would increase licensing less in such countries, and the evidence confirms this. We also show that the effect of the pool is not driven by the products of a handful of large pharmaceutical firms.

Finally, using a dataset purchased from IQVIA, a leading provider of data on international sales of pharmaceutical products, we show that inclusion in the patent pool has significant 
impacts on product market outcomes (drug launches, quantity sold and prices). At the same time, the effect is a combination of different responses by licensees and patentees. The MPP is associated with higher entry rates (launches) of licensees, and this translates to higher quantities of products and lower prices. However, we also find that patentees are less active in the country once a product enters the MPP. This may lead to long term positive effects on consumer welfare, but limited gains in the short term if licensee entry requires longer time than entry from the original innovator.

The effects of the MPP on market outcomes are much smaller than the effect on licensing. This is due to the bundled nature of the pool license contracts, as the model suggests (licensees only launch in a small subset of countries covered by the MPP license) and by a lower propensity of patentees to be active in a country once a product enters the MPP. This point is noteworthy because most studies of pools focus on how they affect licensing. But when licensing is bundled, this will overstate the impact on what ultimately matters, which is commercialization and product entry. Our estimates imply that, in the IQVIA sample (which does not include subSaharan Africa), the probability of observing a licensing deal for product-countries in the MPP is more than 7 times larger than those not in the MPP, but the probability of observing an actual launch by a licensee only increases by 40 percent.

The paper is organized as follows. Section 2 discusses the related literature and Section 3 provides institutional details on the MPP. Section 4 presents a simple conceptual framework. In Section 5 we describe the data and the empirical specification. Section 6 presents the baseline estimates of the effect of the MPP on patent licensing. Section 7 examines the heterogeneity of the effect across countries and firms. In Section 8 we investigate the impact of the MPP on drug launches (entry) and sales. We conclude with a brief summary of the findings and their implications.

\section{Related literature}

This paper is related to three strands of the literature in economics of innovation. The first is the empirical literature on the diffusion of new drugs in developing countries. Cockburn, Lanjouw and Schankerman (2016) show that income levels, and patent and price regulation regimes, strongly affect how quickly new drugs are launched in different countries. Price regulation delays launch, while longer and more extensive patent rights accelerate it. Kyle (2006) examines the role of firm characteristics on pharmaceutical product launches. Kyle (2007) shows that 
price controls significantly retard the speed of launch, as well as the number of countries in which a drug is launched, in the European Union. Duggan, Garthwaite, and Goyal (2016) study the effect of patent protection on drug sales and prices in India. Delgado, Kyle, and McGahan(2013) exploit variation in patent protection generated by the implementation of the TRIPS agreement to examine the effect of patents on prices, quantities and international trade. Dubois, Lefouili and Straub (2021) show that centralized procurement reduces drug prices in low- and middle-income countries. Our paper complements this line of research by examining how patent pools can speed up the diffusion of essential drugs.

The second is the empirical literature on bargaining frictions in the market for technology. Furman and Stern (2011) exploit articles deposited in the Biological Resource Center in the U.S. (BRC), which is a clearinghouse that facilitates access to biomaterials for cumulative innovation. They find that the BRC substantially increases follow-on citations to scientific articles. Williams (2013), Galasso and Schankerman (2015) and Sampat and Williams (2019) provide causal evidence that patent rights retard follow-on research in some technology environments but not in others. A key challenge in this line of research is the lack of comprehensive datasets on transactions in patent rights. These studies on how clearinghouses and patent rights affect follow-on innovation use their findings to infer whether bargaining frictions limit the market for technology. Our paper departs from this approach by relying on patent licensing data both for patents in the pool and for related patents not included in the pool. For some products we even have information on failed negotiations, an aspect no paper in the literature has previously examined.

The third strand is the literature on patent pools. The theoretical work studies the incentives to form pools and the effect of patent pools on innovation incentives (Lerner and Tirole, 2004; Quint, 2014; Llanes and Poblete, 2014; Reisinger and Tarantino, 2019). Empirical work on patent pools is limited and has typically focused on two aspects: the factors that affect the participation decision, including the licensing and governance rules (Lerner, Strojwas and Tirole 2007; Layne-Farrar and Lerner, 2011), and the impact of pools on innovation outcomes (Lampe and Moser, 2013; 2019).

Finally, there are two recent studies on the MPP. Wang (2020) examines the impact of the MPP on pharmaceutical research expenditure, clinical trials and sales of generic drugs. Martinelli et al (2020) study the effect of MPP inclusion on the volume of drugs bought by procurement agencies and on the reallocation of market shares between originators and gener- 
ics. Our paper complements these studies by focusing on the direct impact of patent pooling on licensing and its interaction with market outcomes. We also develop new identification strategies to address endogeneity of MPP patents ad countries, which may also prove useful for future studies using MPP data.

\section{The Medicines Patent Pool}

The Medicines Patent Pool (MPP) is a voluntary licensing and patent pooling mechanism, established in 2010, with a mandate to accelerate access to affordable, appropriate and qualityassured HIV treatments in developing countries. The global health organization UNITAID provided most of the financial support to the establishment of the MPP. In 2015, the mandate of the MPP was expanded to include hepatitis $\mathrm{C}$ and tuberculosis (Medicines Patent Pool, 2018).

The MPP negotiates patent licensing agreements with patent-holding pharmaceutical companies. The medicines to be licensed are identified through in a priority list of drugs both approved and at the pipeline stage. The priority list is defined after consultations with the World Health Organization and experts from the government and the civil society. The choice of drugs takes into account medical needs and patent status in low- and middle-income countries (LMICs).

Once a drug enters the MPP priority list, the MPP approaches relevant patent holders to negotiate for inclusion of the drug in the pool. In negotiating a license deal, the MPP focuses on the public health impact, and aims to obtain broad geographical coverage and freedom to develop pediatric formulations and fixed-dose combinations that meet the needs of resourcelimited settings. MPP licenses are typically royalty-free (more than 60 percent of licenses). In about 30 percent of the licenses royalties are paid to the patentee (typically $5 \%$ of net sales of finished products). In the remaining cases, royalties are collected by the MPP and channeled back to community-based HIV organizations in the country paying the royalty. ${ }^{2}$

Once a license deal with a patent holder is in place ('upstream license'), the MPP issues an expression of interest inviting generic producers to apply for sub-licenses. In striking sub-licenses, the goal of the MPP is to ensure that licensees have the capacity, willingness

\footnotetext{
${ }^{2}$ There is no within-firm variation in royalties in our sample. In particular, the $5 \%$ royalties involve all the HIV products licensed from Gilead, and the royalty channeled back locally is related to the only HIV drug licensed from Bristol-Myers Squibb. This prevents us from identifying the effect of royalties as it would be collinear with the firm effect.
} 
and commitment to obtain appropriate regulatory approval, follow strict quality assurance requirements, develop the formulations and make them available in the licensed territory. MPP sub-licenses are non-exclusive and wide in geographical scope, including up to 131 low- and middle-income countries. Licenses often allow generic manufacturers to sell outside the licensed territory if they are not infringing on a patent.

\section{Analytical framework}

When the market for a pharmaceutical product is small - in terms of number of potential users and per capita income - the costs of negotiating, drafting, monitoring and enforcing a patent licensing contract may exceed the profit that can be extracted. In such cases, a drug company may still be interested in licensing its patents as an investment in corporate social responsibility (CSR) and virtue-signalling, which generates indirect market value (Hong and Liskovich, 2015). A geographic patent pool can increase the private return to CSR investments by absorbing the costs of negotiating and monitoring licenses with generic manufacturers. Moreover, the information about the involvement of the patentee in poor countries may be disseminated more effectively by the pool.

When drug patents are included in a pool, downstream generic manufacturers negotiate with the pool for a bundled license that provides the right to sell the product in multiple countries. This can affect licensing outcomes and product launch decisions. To illustrate this point, we develop a simple model of how a patent pool affects the licensing and drug launch decisions.

A patentee owns two patents related to a pharmaceutical product, one covering country $A$ and another for country $B$. A potential licensee is considering whether to license the patents and commercialize/launch the product. We denote the present value of profits generated during patent protection in market $j$ by $R_{j}$ with $j \in\{A, B\}$. A launch in country $j$ involves a sunk cost $C_{j}$, which includes the cost of securing regulatory approval in the target country and investment in distribution channels and marketing. If the patents are not included in a pool, the patentee and licensee bargain over a bilateral license that grants permission to launch in the countries. The cost of striking a license deal for one country is $c$, and $c+\Delta$ for two countries with $\Delta>0$ and $c+\Delta \leq 2 c$. If the patents are included in a pool, the licensee can only license the bundle (both countries) at a cost $\underline{c} \leq c+\Delta$.

The most natural interpretation of the parameters $c, \Delta$ and $\underline{c}$ is as transaction costs. 
These (private) costs encompass the expenses that a licensee sustains to negotiate, draft and review a patent license contract. We assume that it costs more to negotiate a bilateral patent license contract for two countries than for only one country, i.e. $\Delta>0$, as it involves patents in different jurisdictions and country-specific contractual provisions. The innocuous assumption that $\Delta \leq c$ accommodates economies of scale in bargaining. The assumption that $\underline{c} \leq c+$ $\Delta$ implies that negotiating a two-country license with the pool is less expensive than the corresponding bilateral negotiation. In the context of the MPP, we expect $\underline{c}$ to be low relative to $c+\Delta$ because most aspects of the MPP license contracts are standardized and do not require negotiations. In other contexts, where pool licenses are more tailored toward the specific licensees, the difference between $\underline{c}$ and $c+\Delta$ may be much smaller.

The timing of the game is as follows. In period 0 the licensee decides whether to license the patents. In period 1 the licensee decides whether to pay the $\operatorname{cost} C_{j}$ and enter in each of the countries for which a patent license is in place. Consider first the case where patents are licensed bilaterally. At time 1 the licensee launches in country $j$ only if $\Pi_{j}=R_{j}-C_{j} \geq 0$. At time 0 the licensee will obtain a license for both countries only if the following two conditions are met:

$$
\begin{aligned}
& \Pi_{A}+\Pi_{B}-c-\Delta \geq 0 \\
& \Pi_{A}+\Pi_{B}-c-\Delta \geq \max _{j} \Pi_{j}-c .
\end{aligned}
$$

These conditions require that the expected profits of joint licensing are positive and greater than the profits from licensing in only one country. If these conditions are not satisfied, the licensee will license only one patent and license in the country with the highest $\Pi_{j}$ as long as $\max _{j} \Pi_{j}-c>0$. There will be no license and launch in any country if $\max _{j} \Pi_{j}-c<0 .^{3}$

Now consider a patent pool with bundled licensing for both countries at cost $\underline{c}$. At stage 1 , commercialization in country $j$ will take place only if $\Pi_{j} \geq 0$. Licensing and commercialization in both countries is optimal if the following conditions are satisfied:

$$
\begin{aligned}
& \Pi_{A}+\Pi_{B}-\underline{c} \geq 0 \\
& \Pi_{A}+\Pi_{B}-\underline{c} \geq \max _{j} \Pi_{j}-\underline{c} .
\end{aligned}
$$

\footnotetext{
${ }^{3}$ Our model implicitly assumes that the licensee has full bargaining power and makes a take-it-or-leave it offer to the patentee or the pool. This leads to a royalty free contract which is consistent with the majority of MPP licenses. One can extend the model to include royalties by interpreting $\Pi_{j}$ as net of royalty payments and allowing this variable to differ in bilateral and pool licenses.
} 
These conditions are the same as the bilateral licensing case, except that the licensing cost is now $\underline{c}$ rather than $c$ or $c+\Delta$.

A comparison of these conditions yields two basic empirical predictions. First, a geographic patent pool has an ambiguous effect on the total amount of licensing relative to bilateral contracting. When both $\Pi_{A}$ and $\Pi_{B}$ are large relative to $c+\Delta$, creating a patent pool has no effect on licensing as both patents would be licensed with or without a pool. When the profits that can be obtained in the two countries are asymmetric, the presence of a pool may increase or decrease the number of patents licensed. To see this, consider the case where $\Pi_{A}<0$ and $\Pi_{B}>c$. In this case the firm will only license patent B with a bilateral deal. With a patent pool, the firm license two patents if $\Pi_{B}>\underline{c}$ and no patent if $\Pi_{B} \leq \underline{c}$. We expect $\underline{c}$ to be low relative to $c$ for the MPP, and thus that the MPP should increase licensing.

This simple model compares the licensing through a pool versus direct bilateral licensing. In practice, the MPP does not restrict the ability of participating drug companies to engage also in bilateral licensing. When $\underline{c}$ is low, extending the model to include the choice between bilateral and pool licensing would not change the prediction that the pool increases licensing. However, in a more general setting, the option of using a geographic pool may reduce overall licensing activity when negotiations are costly $(\underline{c}$ is close to $c+\Delta)$ and independent licensing by patentees is not permitted. Thus, the impact of a geographic pool depends on the particular costs involved and restrictions it may impose on participating patentees. This is is consistent with Lerner and Tirole (2004) who show that rules allowing independent licensing affect the participation of firms and the welfare impact of technology patent pools.

The second implication of our model is that, in a patent pool with bundled licensing, the correlation between patent licensing and drug launch may be low. With costly bilateral licensing, the generic firm is expected to launch the product in any country for which it has a license. With a pool, the firm is constrained to license a bundle of countries, in some of which launch may not be profitable. This observation highlights an important distinction between patent pools that license complementary technological components and pools like the MPP which bundle different geographical markets for a given technology. In the first case, one would expect that most, if not all, the licensed patents would be used by the licensee to ensure compliance with the technology standard. This does not apply in pools which serve as clearinghouses for international market access. As a consequence, empirical studies that rely 
on licensing data alone may over-estimate the effect of a pool on actual commercialisation. ${ }^{4}$

Another consideration, outside the lens of our model, is that a geographic patent pool creates a potential coordination problem for licensees. Since licenses give access to a specific set of countries, the pool removes the ability of the patentee to coordinate entry across countries. To see this, consider the case in which markets A and B are natural monopolies, and there are multiple potential licensees. With bilateral licenses, the patentee may restrict entry in each country to only one licensee. This cannot be done when access to both countries is offered through a bundled license by a pool. This implies that the pool may generate a coordination problem in which potential licensees are reluctant to license and launch due to the risk of excessive entry. ${ }^{5}$

\section{$5 \quad$ Data and econometric specification}

Our analysis starts with a balanced product-country-year panel dataset covering the period 2005-2018. The products in our sample were retrieved from three difference sources. First, we download the products listed in MedsPal, a data portal managed by the MPP providing information on key drugs for HIV, hepatitis C, tuberculosis and a few other diseases prominent in low- and middle-income countries. Second, we added to this list all the medicines in the 2017 WHO Essential Medicine List for HIV, tuberculosis, and hepatitis C that were not included in MedsPal. This list is a guide for national institutions in identifying products that need to be available in a functioning health system, and is based on disease prevalence, public health relevance, clinical efficacy and cost-effectiveness. Finally, we include products related to compounds in the $2010 \mathrm{MPP}$ priority list, if these were not included in MedsPal or the Essential Medicine List.

The data set covers 216 products. Each product is defined by a molecule-strength combination (e.g. Abacavir 300mg or Etravirine 100mg). About half (52 percent) of the products are in the 2017 WHO Essential Medicine List. The 2010 MPP priority list includes 83 prod-

\footnotetext{
${ }^{4}$ This also applies to studies in the public health literature (e.g., Juneja et al., 2017) that have tried to estimate the impact of the MPP assuming that its commercial impact takes place in all countries covered by its licenses. In practice, even a technology patent pool may contain patents that are not, strictly speaking, essential for the implementation of a standard. To this extent, some of the patents may not be implemented by all licensees (Lemley and Simcoe, 2018).

${ }^{5}$ This point has been formalized in a one-market dynamic framework by Bolton and Farrell (1990) who show that the coordination problem generated by decentralization may lead to investment delays, especially when there is no substantial private information about the market profitability and when the number of potential entrants is not very large.
} 
ucts. The countries in our sample are the 177 countries listed by MedsPal in July 2019, which includes all countries classified as low- or middle-income by the World Bank and some countries that in recent years graduated to high-income status.

We collected information on the patents protecting products in each country. For 63 percent of the products in our sample, this information is provided by the MedsPal dataset. For the remaining 37 percent ( 80 products), the information was retrieved manually from a variety of sources (including the DrugBank database, the WIPO Pat-INFORMED database and Google patents). Using this information, we identify product-country-years for which there is at least one non-expired patent protecting the product in the country in the focal year.

The final dataset is an unbalanced panel with 80,103 observations encompassing 129 countries and 173 products. ${ }^{6}$ Focusing on product-country-years observations in which patent protection is in place allows us to examine the effect of inclusion of a patent in the Medicines Patent Pool on the likelihood that the patent is licensed in the country. If anything, restricting to this sample leads to an under-estimation of the effect of the pool if licensees also sell in countries where patent protection is not in place. $^{7}$

Our main source of data for patent license agreements is the MPP. In this paper, for clarity, we refer to licensing deals between the MPP and pharmaceutical firms as "upstream licenses", and licensing deals between the MPP and generic manufacturers as "sub-licenses". Finally, we refer to the non-MPP deals between a pharmaceutical company and a generic producer as "bilateral licenses".

Through its web-site, the pool provides open access to the full text of their upstream licensing deals. In some cases, these agreements have been renegotiated over time to include additional countries or drug formulations. The MPP shared with us all the historical contracts, so our data allow us to track how each upstream licensing deal has evolved over time. The pool's web-site also provides information on sub-license agreements between the pool and generic manufacturers for all the drugs in the pool. Data on bilateral (non-MPP) licensing deals is also obtained through the MPP. The MPP discloses, through its MedsPal database, information on

\footnotetext{
${ }^{6}$ We drop products that are listed in MedsPal with patents expired before 2005, those with patents filed after 2018 and products that are not in MedsPal and for which patent information could not be retrieved from other datasets. We drop countries for which our data show no patent filed for all of the products during the entire sample period. These include conflict-affected poor countries (such as Afghanistan and South Sudan) and many very small countries (such as the Cook Islands, Tonga and Mirconesia).

${ }^{7}$ Typically, MPP license deals allow licensees to sell outside the licensed territory as long as they are not infringing on any granted patents. Our discussions with MPP executives suggest that this provision is not present in many bilateral non-MPP deals which may include stricter restrictions on sales.
} 
bilateral licensing deals related to non-MPP drugs. This information is retrieved both from public sources (such as licensors' websites or official press releases) and from non-confidential direct communications to the MPP from the licensors. The information on bilateral licences deals available on the MedsPal portal only covers deals signed after 2010, but the MPP also collected information on bilateral deals signed between 2001 and 2010 and shared it with us for this project.

We construct a variable, Deals, equal to the total number of licensing deals (either bilateral or MPP sublicense) which are in force in the product-country-year observation. We also construct a dummy variable, Access, which is equal to one if at least one of these licensing deals is in force in the product-country-year observation. ${ }^{8}$

\subsection{Descriptive statistics}

By the end of 2018, about 27 percent $(47 / 173)$ of the products in our sample are included in the MPP. Panel A of Table 1 provides summary statistics for some of the key variables in our dataset. The dummy Access equals one for about 18 percent of the product-country-year observations in our sample. Conditional on having at least one license in place, the average number of Deals is equal to 4.6. Of these deals, 1.4 are MPP sublicenses and 3.2 are bilateral deals.

In the appendix we provide a graphical illustration (Figure A1) of the trend in Access for products that enter the MPP by the end of our sample period and those that do not. On average, the likelihood of observing at least one licensing deal is larger in product-countries in the MPP relative to those that are not in the MPP. More strikingly, access for MPP and non-MPP medicines follow a similar trend before 2010, the year in which MPP was instituted, but diverge after 2010 with a substantial increase in access for medicines in the pool. We find a similar pattern plotting the number of deals rather than the indicator variable for country access (unreported).

While illustrative, a simple before- vs. after- 2010 comparison does not take into account that product-country combinations enter the MPP at different times across our sample period.

\footnotetext{
${ }^{8}$ While the number of MPP sublicenses is accurately reported, for some of the bilateral deals we do not know the exact number of licensees involved (but we do know the products involved and the geographic coverage of the deal). This required us to perform two types of imputations in our data. First, we set the number of deals as equal to one in cases where no information on the number of licensees is reported in our data. Second, in some of these cases licensing deals are expanded geographically and we assume that that the revised agreement involves all the original licensees. In the empirical analysis we show that adding a dummy for these adjustments or dropping these subsamples has no impact on our findings.
} 
To address this, Panel B of Table 1 provides preliminary evidence of the effect of a countryproduct entering the pool. The first row shows the baseline probability of at least one MPP license (Access) and the average number of deals for country-product combinations that are not included in the MPP during our entire sample period. The second row presents the same information for country-products that enter the pool, for the sample years before their inclusion in the MPP. The last row provides similar statistics for country-products in the pool during the sample period in which they are included in the MPP. The results are striking. Access rates are respectively $0.13,0.09$ and 0.87 , implying that the probability of striking at least one license deal related to the product-country increases is nearly 10 times larger once the product-country is included in the MPP. Similarly, the average number of deals are 0.48, 0.45 and 5.45. These are very large effects, but they may confound the causal effect of pool inclusion with unobserved heterogeneity driven by country and product characteristics. The econometric analysis below attempts to control for these dimensions of heterogeneity.

As emphasized earlier, given the bundled licensing by the MPP, patent license deals capture "potential generic entrants" for the product/country rather than "actual entry." In Section 8 we examine this distinction in detail, using drug launches and sales data purchased from a private vendor.

\subsection{Econometric model}

Our empirical strategy relies on a difference-in-differences estimation:

$$
Y_{p, c, t}=\alpha+\beta M P P_{p, c, t}+\gamma X_{c, t}+\delta_{t}+f_{p, c}+\varepsilon_{p, c, t}
$$

where the dependent variable, $Y_{p, c, t}$, captures licensing activities in product, $p$, country, $c$, and year $t$. The unit of observation is a product-country-year. The treatment variable, $M P P_{p, c, t}$ is equal to one for product-countries that are included in an upstream license between MPP and a pharmaceutical firm in year $t$. The term $X_{c, t}$ captures a series of time-varying country controls. The terms $\delta_{t}$ and $f_{p, c}$ are year and product-country fixed effects. The coefficient $\beta$ is a difference-in-differences estimator identifying the effect of entering the pool on licensing relative to product-countries that are not in the MPP.

The baseline regressions are estimated by OLS, with standard errors clustered at the product-country level. Section 6.2 confirms robustness of our findings using alternative specifications that account both for the count nature and other features of our data. In Sections 6.3 and 6.4 we develop two identification strategies to address endogeneity concerns. Each reduces 
the usable sample size, so we begin with the OLS applied to the full sample.

\section{Empirical Results}

\subsection{Baseline specification}

Table 2 provides the baseline results. In column 1, the dependent variable is Access, an indicator equal to one if at least one licensing deal is in place for product $p$ and country $c$ in year $t$. The estimated parameter $\beta$ is positive and statistically significant: the likelihood of at least one deal for the product-country increases by 66 percentage points after the product-country combination enters the MPP. Since the mean value of Access for non-MPP products-countries is 0.13 , this corresponds to a 5 -fold increase in the likelihood of observing at least one licensing deal. In column 2 the dependent variable is the total number of licensing deals. The estimated MPP treatment effect is an increase of 4.6 deals, and it is strongly significant. Compared to the average number of deals for product-countries that never enter the MPP, this represents a 10 -fold increase.

Columns 3 and 4 estimate a more flexible specification in which the effect of MPP is allowed to vary during the first five years after entry into the pool. The estimates confirm the positive association between inclusion in the MPP, Access and licensing deals. The coefficients become large and statistically significant immediately after a product-country enters the pool and monotonically rise over time. This indicates that the growth in licensing deals that follows entry in the MPP begins very quickly, during the first couple of years, and solidifies over time with new deals struck even five years after MPP inclusion. ${ }^{9}$ Finally, in column 5 we check whether licensing deals rose in the two years prior to the product-country entering the MPP. The estimated coefficients are small and statistically insignificant, indicating that entry into the MPP was not associated with pre-entry trends.

Overall, the monotonic pattern of the timing of the MPP effect is in line with the simple plot of raw-data in Appendix Figure A1. An important caveat is that Figure A1 compares Access before and after 2010, the year in which MPP was established. Because most of the products-countries in our sample entered the MPP two to three years after 2010, the bulk of the increase in deals takes place a few years after MPP establishment. Conversely, the regression analysis, which focuses on differences before and after the inclusion of a product-country in the

\footnotetext{
${ }^{9}$ To address truncation concerns, we estimate these specifications dropping from the sample product-country pairs that are in the MPP for less than 4 years. Results are similar if we use the full sample.
} 
MPP, shows that deal growth starts quickly after MPP inclusion.

\subsection{Robustness}

We perform a variety of tests to confirm robustness of our main finding. Appendix Table A1 shows that the relationship between MPP and deals is robust to using alternative econometric specification. We re-estimate the baseline model using Poisson and Negative Binomial specifications, and confirm the strong and statistically significant positive correlation. The estimated coefficient in the Poisson model implies that product-country pairs in the MPP experience 370 percent more deals than their non-MPP counterparts. ${ }^{10}$

The dependent variables used in our baseline analysis are stock variables based on the number of licensing deals that are in place in a specific product-country-year. A cumulative measure is preferable in our setting since licensing deals are long lasting, and the total number of generic firms with a license agreement in place captures more directly the potential supply and competition in the country. In Appendix Table A1 we redo the analysis with flow versions of the dependent variables, and the results are in line with the baseline specification - the flow of licensing deals sharply increases after a product-country enters the MPP.

Part of the effect we estimate in Table 2 is mechanically due to extension of existing upstream deals to new countries. When the MPP and upstream drug company agree to revise an existing license to include additional countries, the existing sub-licensees automatically gain immediate access to the newly listed countries. To remove this effect, Appendix Table A2 re-estimates columns 3 and 4 of Table 2 using only the countries listed in the first upstream deal between the MPP and the upstream drug company and dropping the product-country combinations that enter the MPP through a revision of an existing deal. The coefficients in these regressions are only slightly lower than those estimated in Table 2, indicating that the treatment effect is not driven by a broadening of the existing sub-licenses. ${ }^{11}$

Finally, our analysis defined products by a molecule-strength combination, even though

\footnotetext{
${ }^{10}$ Table A1 also confirms the result using the logarithm of the number of deals (plus one) as dependent variable. The results are also robust to two alternative corrections of the dependent variable with values of zero in the $\log$ specification - specifically, we add 0.01 instead of 1 to the zero value, and include a dummy control for observations with zero deals. We also re-estimated the specification with Access as dependent variable using a proportional hazard survival model with an exponential distribution. We find that the effect of the MPP is a very large increase in the hazard of Access, confirming our finding with the OLS specification.

${ }^{11}$ Because of missing information in our data, some of the number of bilateral deals in our sample had to be imputed. Appendix Table A2 takes this into account by adding a dummy for observations in which the number of deals was not precisely measured and by dropping these observations from the sample. Overall this has no impact on our estimates, indicating measurement error associated with these imputed deals is not a problem.
} 
pharmaceutical patents often cover an entire molecule. There are two reasons why this is the more appropriate level of analysis in our setting, rather than the molecule level. First, many of the licenses in our data only cover a subset of the products related to a molecule. This is particularly the case for licenses that focus on pediatric or adult formulations. For example, the MPP licenses on the pediatric formulations of abacavir includes the $60 \mathrm{mg}$ but not the $300 \mathrm{mg}$ version of the product. Second, several products in our sample are combinations of multiple compounds and are protected both by molecule patents and patents on combination therapies and layered tablets. Nonetheless, in order to confirm that our results are not driven by the disaggregated nature of the data, we re-estimate our baseline regressions using data at the molecule-country level. The results are very similar to those based on molecule-strengh-country level (Appendix Table A2). ${ }^{12}$

\subsection{Potential endogeneity of medicines in the MPP}

One potential concern is that products are not likely to be randomly allocated to the patent pool. There may be unobservable factors that are correlated both with the likelihood that the product enters the MPP and the underlying demand for licenses for that product. The direction of the induced bias is ambiguous, however, and would depend on how the MPP decides which products to target. For example, the MPP may decide not to target the most effective drugs with large demand, as it may anticipate that there would be a large number of licenses for these products even without their intervention. This would induce a negative bias in the OLS regression of licensing against MPP inclusion. At the same time, the MPP may not consider drugs with niche markets and small demand, as it might expect no licensing interest even if the drugs were included in the MPP. This would induce a positive bias in our estimates.

To address this issue, we exploit the MPP 2010 priority list. This list of medicines was compiled when the pool was established, after consultations with the WHO, national governments and other experts. It comprises medicines that the MPP wanted to be included in the pool in 2010. For all these drugs, MPP entered a negotiation with the pharmaceutical company owning the patent. The 2010 priority list encompasses 83 of our sample products, but only 38.5 percent of them eventually made it into the MPP. Under the assumption that success/failure

\footnotetext{
${ }^{12}$ In these regressions we re-define the MPP dummy as equal to one if at least one product related to the molecule-country is included in an MPP license, and measure Deals as the maximum number of licensees across the products related to a molecule-country. In Appendix Table A2 we drop product combinations, and cluster standard errors at the molecule-country level. Results are similar when we treat each combination as if it was a separate molecule or when we cluster the standard errors at the molecule level.
} 
in the negotiation for these drugs was quasi-random - i.e. not related to unobservable drivers of future licensing - focusing on this priority list would alleviate concerns related to selection into the MPP. ${ }^{13}$

In short, we use the drugs for which negotiations failed as a counterfactual for what would have happened to the drug that entered the pool in the absence of pool inclusion. The key identification assumption is that drugs in the 2010 priority list would have trended identically in the absence of MPP inclusion, conditional on the other control variables. This identification strategy is similar to the one employed by Greenstone et al. (2010), who estimate the effect of large plant openings in a county using counties that were considered by the plant managers, but not chosen, as a counterfactual. Columns 1 and 2 in Table 3 provide the resulting estimates of the MPP treatment effect on Access and the number of deals. The results are similar to those in our baseline regressions, indicating that product level selection into the MPP does not seem to be a source of bias.

One remaining concern is that there could be confounding, time-varying unobservables that are correlated both with success of the negotiations and with the number of downstream licensing deals executed. For example, during the negotiations new information about the potential market may be revealed that changes the interest of the pool in the medicine as well as subsequent bilateral deals. Discussions with MPP executives identified one such case, Etravirine whose product-country observations account for roughly 6 percent of our sample. During the negotiation new market information was revealed that the medicine would only have a niche market, and led the MPP to drop its negotiation with the patentee. This would induce an upward bias in the estimated MPP effect. In columns 3 and 4 of Table 3 we drop this drug from our sample and re-estimate the baseline model. The point estimates are indeed smaller, but the magnitude of the change is small. ${ }^{14}$

Finally, in column 5 we re-estimate the model including effects for the two years before

\footnotetext{
${ }^{13}$ Using failed negotiations over drugs in the priority list should also take care of another possible concern. Specifically, a licensee might decide to delay a bilateral negotiation over a product-country once it learns that the MPP is negotiating with a pharmaceutical company. Since this information is available at the same time for both treatment and control group, such strategic delay should not cause any bias.

${ }^{14}$ An additional concern is that positive shocks to the product's profitability may lead patentees to keep the market for themselves and not license the product neither through the MPP or bilateral deals. This would lead us to over-estimate the effect of MPP, as negotiations that break down will be associated to products with less bilateral deals. Our baseline estimates are robust to controlling for commercialization activity by the original patentee, suggesting that this mechanism is not generating bias in our estimates. In Section 8 , we discuss the data used to identify patentee commercialization and examine additional issues related to product market outcomes.
} 
the product-country entered the pool. The coefficients are small and statistically insignificant, indicating that, prior to MPP entry, there was no difference in trends in licensing deals for products with successful and failed negotiations.

\subsection{Potential endogeneity of countries in the MPP}

Our baseline regression includes product-country fixed effects which account for stable characteristics that may be correlated with upstream and downstream licensing. However, there could be time-varying country characteristics that affect both the inclusion of countries in MPP licenses and their bilateral licensing. For example, the introduction of government policies that make the market more attractive to the patent-holding drug companies may make bilateral licensing more likely and thus make it less likely that the country will be covered by the upstream license with the MPP. In this sub-section we address this potential source of endogeneity.

\subsubsection{Country controls}

As a first step, we extend the baseline specification by including time-varying demographic features of the sample countries. These variables are taken from the World Bank data portal. ${ }^{15}$ Columns 1 and 2 of Table 4 show that our baseline results are robust to including controls for the log of population in the focal year. In columns 3 and 4 we add controls for the prevalence of HIV in the country (measured as the percent of the population living with HIV) and percapita health expenditure. Licensing deals appear strongly correlated with the population of the country, the prevalence of HIV and, to a lesser extent, with the country health expenditure. The estimates of the MPP effect on Access is stable but the coefficient on Deals drops by about half. ${ }^{16}$

Introducing the World Bank controls substantially reduces the sample size, as some of those variables are only available for a subset of countries. In column 5 and 6 we follow a different approach that exploits the full sample by including a full set of country-year effects that capture any time-varying factors in the economy of the country. In this more demanding, specification, the size of the MPP coefficients falls by about 20 percent relative to the baseline (columns 1 and 2 in Table 2), but the MPP effect remains statistically significant and

\footnotetext{
15 We drop countries that have no data for the survey variables for entire sample period, and interpolate missing values for incomplete series.

${ }^{16}$ It is difficult to interpret the coefficients on these controls, as these are reduced form coefficients and there can be various mechanisms at play.
} 
economically large.

\subsubsection{Fuzzy regression discontinuity design}

The second identification strategy to address endogeneity of MPP countries exploits the fact that the MPP targets countries in the low- or lower middle-income bracket. This allows us to implement a fuzzy regression discontinuity design. This approach provides a more convincing counter-factual for countries included in the MPP, but it has the disadvantage it relies on local cross-sectional variation and thus is based on a much smaller sample.

Discussions with MPP executives indicate that the pool considers a variety of factors when negotiating the geographical scope of a deal. One prominent element is the income level of the country and special attention is given to the income groupings provided by the World Bank. Each year the World Bank classifies countries into income categories distinguishing between low-income, lower middle-income, upper middle-income and high-income. ${ }^{17}$ The mission of the MPP, as stated on their web-page, is to increase access to, and facilitate the development of, life-saving medicines for low- and middle-income countries.

High-income countries are typically excluded from MPP deals. The distinction between lower and upper middle-income plays an important role. The typical upstream MPP license includes a large number of lower middle-income countries but only a handful, if any, of upper middle-income countries. This is both because drug companies see greater potential for bilateral deals for the upper middle-income group (e.g. Brazil or China) and because the MPP itself has less interest in such countries (Branigan, 2018). We confirmed this directly with MPP executives, who reported that companies often use the upper middle-income thresholds as a key criterion for agreeing whether to include a country into the upstream license.

Figure 1 illustrates how the World Bank classification status affects the likelihood of entering the MPP. To construct this figure, we focus on drugs that enter the MPP during our sample period and identify countries that were within a $\$ 500$ window below and above the upper middle-income threshold in the year in which the drug joined the pool. The difference in the likelihood of inclusion in the pool is striking and significant at the 0.01 level. About 56 percent of the product-country dyads related to lower middle-income countries are included

\footnotetext{
${ }^{17}$ This classification exploits thresholds of gross national income (GNI) per-capita calculated using the World Bank Atlas method. For example, in 2018 low-income economies were defined as those with a GNI per capita of $\$ 1,025$ or less; lower middle-income economies are those with a GNI per capita between $\$ 1,026$ and $\$ 3,995$; upper middle-income economies are those with a GNI per capita between $\$ 3,996$ and $\$ 12,375$; high-income economies are those with a GNI per capita of $\$ 12,376$ or more.
} 
in the pool, whereas only 18 percent of those in upper middle-income bracket enter the MPP. Within the same narrow income bracket, we cannot reject equality between lower and upper middle-income countries in terms of logarithm of population ( $\mathrm{p}$-value $=0.32$ ), percentage of population affected by HIV ( $\mathrm{p}$-value $=0.36)$ and health expenditure per capita ( $\mathrm{p}$-value $=0.54)$. These tests support the idea of covariate balance, i.e. that countries in the neighborhood of the threshold are similar to one another in their observable characteristics.

This evidence motivates a fuzzy regression discontinuity design where we use a dummy for whether the country is below or above the upper middle-income threshold as an instrument for inclusion in the MPP. The IV estimator captures the local average treatment effect for the sub-set of countries for which inclusion in the MPP is affected by the instrument, under the exclusion restriction that the World Bank classification does not affect licensing negotiations directly -i.e., through channels other than the MPP (Lee and Lemieux, 2010).

To implement the fuzzy RD design, we re-shape our dataset as a cross-section and estimate the following specification:

$$
Y_{p, c}=\alpha+\beta M P P_{p, c}+E_{\text {Entr_year }}+\varepsilon_{p, c}
$$

The unit of observation is a product-country. The dependent variable is the total number of licensing deals in a time widow after the inclusion in the pool. The term Entry_year $p$ captures any macroeconomic effect in the year the product enters the pool. We instrument MPP with the World Bank status of the country at the time of inclusion of the product in the MPP. The sample only includes products that enter the MPP by 2018. A cross-sectional dataset is required because the IV does not vary over time for a product-country. The focus on products that enter the MPP is required because the instrument is not defined for products that are not included in the MPP. ${ }^{18}$ We estimate equation (2) on the sub-sample of product-countries for which countries had GNI per-capita within a small window around the World Bank upper middle-income threshold at the time of inclusion of the product in the MPP.

Column 1 in Table 5 provides the OLS estimate of (2) for the sub-sample. The GNI per-capita window is between $\$ 1,385$ below and $\$ 1,675$ above the World Bank threshold. This sample comprises 352 observations which represent 30 percent of the product-country dyads involving middle-income countries. The sample is equally split above and below the threshold. Despite the much smaller sample size, the point estimates confirm the findings in the baseline

\footnotetext{
${ }^{18}$ We also restrict attention to the first negotiated deal, dropping country-product dyads that are included in the sample after a re-negotiated deal. Results are similar if we include these dyads.
} 
specification - the MPP is associated with an increase of 5.4 licensing deals in the 3 -year window that follows inclusion in the pool.

Column 2 reports the first stage regression, confirming a strong negative correlation between the upper middle-income status of the country and inclusion in the MPP. Column 3 presents the parameter estimates from the IV regression. The estimated coefficient on MPP is larger, but not statistically different, from the OLS estimate. Column 4 narrows the sample only including observations where countries are within $\$ 500$ of the upper middle-income threshold. The sample size is reduced to only 108 observations, but we still find a significant MPP effect. Though it is larger, it is not statistically different from the estimate in column 3.

One might be concerned that upper middle-income status may affect licensing negotiations through channels other than the MPP (violating the exclusion restriction). The main candidate is financing by the Global Fund (GF) a large international organization which supports programs targeted at AIDS, tuberculosis and malaria. Eligibility to receive GF financing is driven by a variety of factors, including World Bank income status. While all low- and lower middle-income countries are eligible, not all upper middle-income countries are eligible. To check whether our estimated MPP effect is affected by changes in GF financing eligibility, we collect information provided in the GF web-site and re-estimate the IV specification where we include a control for the eligibility of the country for GF financing around the time the drug entered the MPP. The coefficient on the (instrumented) MPP variable is essentially identical to the one in column $3(6.67$, p-value $<0.01)$, lending credence to the exclusion restriction.

Appendix Table A3 provides additional evidence on the robustness of the findings. We exploit the MPP 2010 priority list and expand the sample to include a set of products that do not enter the MPP but for which a negotiation started in 2010. ${ }^{19}$ This sample alleviates concerns related to the endogeneity of MPP products (by contrasting those where negotiations succeeded and failed) and the endogeneity of MPP countries (by instrumenting MPP inclusion with World Bank status). The estimated coefficient is 4.95 (p-value $<0.01$ ), slightly smaller but in line with those estimated in Table 5. The appendix table also shows robustness to widening the window to five years for the number of deals and the Access dummy, and to including controls related to country size, prevalence of HIV and the size of its health care system.

\footnotetext{
${ }^{19}$ For the medicines whee negotiation failed, we impute 2011 as year inclusion, implicitly assuming that one year was required to negotiate the deal. Results are robust to alternative assumptions.
} 


\section{Heterogeneus treatment effects}

To this point we have assumed that the effect of the MPP on licensing is constant across countries and products. In this section we examine the heterogenous impact of the MPP by relating it to observable characteristics of the country. We also briefly discuss heterogeneity across patentees and products.

\subsection{Country heterogeneity}

We examine whether the impact of the MPP on licensing varies across characteristics of the destination country. We distinguish countries along two dimensions. The first group is countries with high prevalence of HIV-infected individuals. We identify the top four countries in term of average absolute number of people living with HIV during our sample period: South Africa, Nigeria, Kenya and Mozambique. ${ }^{20}$ These countries are more attractive markets for upstream drug companies, and thus more likely to have bilateral licensing deals. Thus we would expect the impact of coverage by the MPP (relative to bilateral licenses) to be smaller.

The second group is countries that are small (population in the first quartile of our sample) and that are not in Sub-Saharan Africa. Countries with these features are likely to attract fewer bilateral deals, given that their market demand is limited. Thus, we expect the impact of being included in the MPP to be larger. ${ }^{21}$

Columns 1-3 in Table 6 show the impact of the MPP on licensing varies sharply along these dimensions. The probability of at least one deal (Access) increases substantially once a small, non Sub-Saharan country is included in the MPP. Conversely, the effect on Access is much less pronounced for the countries with the largest incidence of HIV. This result is robust across various specifications. Column 1 includes year and product-country effects. Column 2 includes additional covariates to capture demographic characteristics - log population, percentage of population with HIV, and health expenditure per capita. Column 3 includes country-year effects.

Columns 4-6 present similar regressions using the number of deals as the dependent variable. Here the coefficients on the interaction of MPP and country characteristics are very

\footnotetext{
${ }^{20}$ Results are robust to picking the top 3,5 or 6 countries.

${ }^{21}$ These countries include: Albania, Antigua Barbuda, Armenia, Barbados, Belize, Bosnia Herzegovina, British Virgin Islands, Costa Rica, Fiji, Georgia, Grenada, Guyana, Jamaica, Kiribati, Kosovo, Lebanon, Macedonia, Moldova, Mongolia, Montenegro, Nauru, Panama, Saint Lucia, Solomon Islands, Trinidad Tobago, Turkmenistan, Turks Caicos, Tuvalu, Uruguay and Vanuatu.
} 
small relative to the direct effect of the MPP, and not statistically significant. Overall, the estimates in Table 6 show substantial country heterogeneity at the extensive margin (going from no license to one license) but not at the intensive margin (number of deals). The main reason behind this asymmetry is that MPP downstream deals allow licensees to access a bundle of heterogeneous countries. Therefore, any additional MPP licensee increases the number of deals in an MPP country by one, independently of country characteristics. Provided there is only limited substitution with bilateral deals, the effect of the MPP on the total number of licensing deals will be more similar across heterogenous countries. ${ }^{22}$

These results show that the MPP is more important in generating additional licensing deals for small, non-Sub-Saharan countries where there is lower exposure to HIV. In this respect, the pool represents a gateway to needed drugs for countries that are neither big enough to be an attractive market, nor able to generate 'halo' effects for upstream drug owners.

\subsection{Other dimensions of heterogeneity}

We also explored two additional sources of heterogeneity. First, we examine whether the effect may be driven by the products of a handful of large pharmaceutical firms by re-estimating the baseline where we drop (one at a time) each of the three largest pharmaceutical companies in our sample (accounting for 52 percent of the sample) - Gilead, ViiV and Janssen. Unreported results shows that our findings are robust to dropping each of these players. The largest change occurs when we drop Gilead, where the estimated coefficient is about 20 percent lower than the one in the full sample, but still large and statistically significant. ${ }^{23}$

Second, we examined whether the effect of the MPP on licensing is stronger for products relying on a combination of compounds ("drug cocktails") relative to single compound products. About 40 percent of the products in our sample involve combinations of multiple compounds. If the compounds are owned by different patentees, bilateral bargaining failure

\footnotetext{
${ }^{22}$ To gain the intuition for this, consider the following illustrative example. A drug is available for license in two countries: Albania and South Africa. Assume that in the absence of MPP there are no licensees in Albania and 4 licensees in South Africa. Assume that both countries are included in the MPP license for the drug and that 3 sub-licensees sign up. The number of deals increases by 3 in both countries, but the dummy Access changes from 0 to 1 in Albania and is not affected in South Africa.

${ }^{23}$ Our results are also robust to a specification which includes firm-year effects, which capture time-varying, firm-level unobservables. We also examined how upstream drug firms react to inclusion of their patents in the MPP in terms of their bilateral licensing activity. The bilateral deals of Gilead appear to react positively to MPP inclusion. For all other firms, the effect of MPP on bilateral deals is small, negative and, in most specifications, statistically insignificant. This suggests that the pool had a differential effect on the licensing strategies of upstream drug companies. A detailed examination of this issue is outside the scope of the paper but a potentially fruitful direction for future research.
} 
is more likely in those cases, so being covered in the pool would have a larger impact. The estimated impact of the MPP on Access is $7.3 \%$ larger for combination products, and $15.4 \%$ larger when we use Deals as the dependent variable and the differences are statistically significant. $^{24}$ This points to some bargaining failure but the difference is modest. The explanation for this result is that many combinations in our sample involve compounds licensed by the same company (e.g., many cocktails mix subsets of tenofovir, emtricitabine, cobicistat, and elvitegravir, all licensed by Gilead). Other combinations are a mix between a patented compound and older compounds no longer subject to patent protection (such as abacavir/lamivudine or dolutegravir/lamivudine). These features make negotiations over combinations quite similar to those related to one compound products.

\section{Drug launches and sales}

Thus far we examined the impact of the MPP on downstream licensing deals. These contracts give licensees the right to practice the patented product, but they may not necessarily translate into actual launch and sales. In short, patent license deals measure potential entry of the generic firms rather than actual entry. This distinction is important in our setting where MPP license contracts include large bundles of countries, as licensees are likely to only be interested in a subset of the countries. Moreover, even if the generic firm does launch and sell in a country, the patentee may react by withdrawing from the market when the product is covered by the MPP.

To examine this issue requires data on actual entry by generic firms and their sales across the countries in our sample. We purchased a dataset with this information from a private vendor, IQVIA, a leading provider of data on international sales of pharmaceutical products. The IQVIA data provide detailed information on the launch of new products across countries, sales revenues (in US dollars) and volume (number of packs) for the period of our study. Despite this level of detail, the IQVIA data do not cover our full sample. Data on sales are only available for 32 countries out of the 129 countries in our sample. The countries for which we have data are mostly middle-income countries outside Sub-Saharan Africa (such as Egypt, Pakistan, Peru and Vietnam). ${ }^{25}$ In terms of products, IQVIA information covers about

\footnotetext{
${ }^{24}$ Using Access as the dependent variable, the split-sample estimates (standard errors) are 0.688 (0.012) for combinations and 0.641 (0.016) for single compound products. For Deals, the coefficients are $4.938(0.152)$ and $4.280(0.161)$.

${ }^{25}$ This is an important difference with other contemporaneous studies examining the effects of the MPP.
} 
80 percent of the products in our sample.

Matching these data with our licensing dataset, we obtain an unbalanced panel with 24,663 product-country-year observations. Because many Sub-Saharan and poor countries that are often included in MPP agreements are not present in the IQVIA data, the dummy MPP is equal to one for only 3.6 percent of the sample (compared to 7 percent in the licensing sample). For about 75 percent of the sample, we observe no firm active in the product-country, i.e. no firm has launched the product in the country by that year. On average, at least one licensee launches a product in about 7 percent of the observations. ${ }^{26}$

\subsection{Impact on entry}

Table 7 provides evidence on how inclusion of a country-product in the MPP affects market outcomes. In column 1 the dependent variable is a dummy equal to one if at least one firm has launched the product in the country in the focal year. The regression shows a decline of about 5.1 percentage points in the likelihood of having at least one active entrant during the first four years after inclusion in the MPP, with this decline moderating each year (the estimated coefficient is statistically insignificant after the fourth year). This represents a 20 percent decline relative to the mean for non-MPP products-countries.

That decline in entry after coverage by the MPP may seem surprising at first blush. Columns 2 and 3 show that this result is due to a lag in generic entry combined with retrenchment by the patentee once the product-country enters the MPP. Column 2 shows that inclusion in the MPP increases the likelihood that at least one licensee launches the product in the country, but this entry takes place with a delay. This delay is consistent with information reported in the MPP web-site and MPP publications on the timing required for licensees to sell once a patent deal is in place, as commercialization requires setting up manufacturing and distribution facilities as well as obtaining WHO prequalification of the generic version of the drug. ${ }^{27}$ At

They focus on transactions that rely on resources from international organizations, such as the Global Fund, which predominantly operate in Sub-Saharan Africa. The IQVIA data includes local sales financed by these organizations as well as other local sales to local governments and private entities.

\footnotetext{
${ }^{26}$ Despite the smaller sample, the relationship between licensing and inclusion in the MPP replicates well in the IQVIA sample. The coefficient in the regression of Access on the MPP dummy is 0.691 (p-value $<.01$ ), and for the number of deals the coefficient $4.241(\mathrm{p}$-value $<.01)$. These are similar to the baseline estimates in column 1 and 2 in Table 2.

${ }^{27}$ Take, for example the drug Dolutegravir (DGT) which entered the MPP in April 2014 and is highlighted by the pool as one of the MPP medicines with faster penetration in developing countries. A number of licensees signed up a downstream agreement shortly after MPP inclusion - e.g., Cipla in June 2014 and Mylan in July 2014. MPP documents report that these two companies applied for prequalification of generic DTG in November
} 
the same time, column 3 shows that, after MPP coverage, the likelihood of a product launch by the original patentee falls and this effect occurs quickly.

In short, the pool increases the likelihood of generic entry by licensees with a lag, but reduces entry by the upstream patentee. This yields a U-shaped impact of the MPP on the product launches and diffusion. ${ }^{28}$

\subsection{Impact on sales}

With the available data, it is not possible to identify the effect of the MPP on the number of entrants (degree of competition) for a given product-country. For about 70 percent of productcountry-years in which entry occurs, there is only one active firm. Our attempts to estimate the impact of the MPP on the number of entrants indicated small effects, but they were very imprecise. As an alternative approach, we focus on the impact of the MPP on sales directly, as reported by IQVIA.

In column 4 of Table 7, we examine the effect of the MPP on the log of total sales (plus one) in U.S. dollars for the product in the country during the focal year. The impact on total sales is very limited, but this confounds countervailing effects on quantities and prices. Column 5 runs the same regression using the volume of product sold as the dependent variable. ${ }^{29}$ Here the estimates indicate an increase in quantity sold, especially after the fourth year of entering the MPP. Together, columns 4 and 5 suggest that inclusion in the MPP leads to higher quantity sold and an associated (implied) decline in market prices. ${ }^{30}$

Together, the null effect on revenue and the positive effect on quantities suggest that

2016 and that no shipment to developing countries took place before the spring of 2017.

\footnotetext{
${ }^{28}$ IQVIA also provided us with partial data on product launches for seven additional countries, all former members of the Commonwealth of Independent States (CIS): Armenia, Azerbaijan, Kazakhstan, Kyrgyzstan, Moldova, Tajikistan, and Uzbekistan. For these countries we do not have information on volume or sales. Moreover, information on launches is aggregated at the molecule level (i.e., not by dosage) and it is available only for a subset of molecules accounting for about 55 percent of the products in our sample. We re-estimated columns 1-3 of Table 7 at the more aggregate molecule level, including these countries but restricted to the subset of available compounds. The results, reported in Appendix Table A4, are broadly consistent with the findings of Table 7. The likelihood of observing at least one licensee selling increases after a few years but it is countervailed by an equivalent decline in the activity of original patentees.
}

\footnotetext{
${ }^{29}$ For both dependent variables, we add a dummy equal to one for sales equal to zero. Volume is constructed at the product level adjusting the IQVIA data on packs sold for the number of vials or tablets in each pack.

${ }^{30} \mathrm{An}$ analysis of market prices (computed as sales/volume) is difficult in our setting as prices are not defined when there are no sales in a country. If we impute a value of zero and control with a dummy for those (numerous) cases, we find a negative correlation between MPP inclusion and market prices, statistically significant at the 0.01 level after four years of inclusion.
} 
the underlying demand has an elasticity of about (minus) one. This is consistent with the estimates in Kremer and Snyder $(2015,2018)$, who show that the distribution of HIV infection risk approximates a Zipf distribution, which in turn yields a unit elastic demand. In a recent study of the impact of drug procurement systems on prices in low- and middle-income countries, Dubois et al. (2021) also find elasticities in the vicinity of one. ${ }^{31}$

In summary, the evidence shows that inclusion in the patent pool promotes entry and diffusion of essential medicines, but the effect is a combination of different responses by licensees and patentees. While the MPP is associated with entry of licensees selling higher quantities of products, patentees appear less active in the country once a product enters the MPP. This may lead to long term positive effects on consumer welfare, but limited gains in the short term if licensee entry requires time.

There are two important caveats. First, more than half of the MPP product-countries in our sample were included in the pool in the past five years. For these licensees, manufacturing and launch are still underway, so our time window may not be adequate for a full examination of sales. Second, the IQVIA data do not include some poor and Sub-Saharan countries that are often target of MPP deals. Future research using a longer time span and additional countries would allow us to learn more about the market, and thus welfare, effects of the MPP.

\subsection{Discussion and potential welfare effects}

We have shown that entry into the MPP leads to a very large and immediate increase in the likelihood of observing at least one licensee for the product-country. Our simple model explains this as being driven by a reduction in transaction costs. An alternative explanation, however, is that the increase is due to more favorable licensing terms provided by the pool to generic producers relative to bilateral licenses. Unfortunately, we do not have information on the terms and conditions of the bilateral deals in our sample, so we cannot directly test this alternative hypothesis. Nonetheless, there are several reasons why we expect the differences in licensing terms not to be substantial. First, media statements released by pharmaceutical companies after the implementation of bilateral agreements indicate that royalties are often low or zero. ${ }^{32}$

\footnotetext{
${ }^{31}$ Specifically, they estimate the demand elasticity at about -0.88 ; it ranges from -0.73 to -0.97 , depending on the type of procurement system. Their analysis uses a wider set of molecules than the one in our data (including but not limited to HIV and tuberculosis) and it is limited to seven countries.

${ }^{32}$ For example, the 2011 license between Bristol Myers Squibb and Matrix Laboratories for stavudine and didanosine in Sub-Saharan Africa is royalty free. The same is true for a number of Boehringer-Ingelheim's licenses of nevirapine in low-income countries.
} 
Second, many of the bilateral deals in our sample focus on Sub-Saharan Africa or other lowincome countries, which have limited potential to generate royalty income in any case. Finally, there is some anecdotal evidence that the MPP designed some of its downstream licenses using drug companies' bilateral contracts as templates. ${ }^{33}$

Our analysis also shows that the likelihood of at least one licensee launching the product in the country increases after entry into the MPP. However, the size of this effect on launch is much smaller, and more delayed, than the impact on licensing. This is consistent with the theoretical discussion in Section 4, where we pointed out that MPP contracts constrain licensees to license a bundle of patents which may include markets for which a launch is unprofitable. We can use our estimates to get a better sense of the relative size of these effects. First, predicted values from our baseline regression (column 1, Table 2) - constructed using means of covariates and including the estimated fixed effects - imply that the probability of observing at least one license is 0.11 for product-countries that are not in the MPP, and equal to 0.84 for those in the MPP. Second, predicted values of an unreported regression of launches on Access indicate that the presence of one licensing deal translates into an actual launch with probability 0.62 for product-countries that are not in the pool and with probability 0.12 for those covered by the MPP. ${ }^{34}$

Together, these estimates imply that, in country-products not covered by the pool, the probability of observing one launch is about $0.07(=0.11 \times 0.62)$, and that this probability is equal to $0.10(=0.84 \times 0.12)$ for product countries included in the MPP. In short, our empirical analysis implies that inclusion in the MPP increases the probability of licensing by 73 percentage points (from 0.11 to 0.84 ), but it increases the probability of observing an actual launch by only 3 percentage points (from 0.07 to 0.10 ). This finding has an important implication for empirical research on patent pools with bundled licensing, as it shows that focusing on licensing can be very misleading as to the impact of the pool on actual entry and diffusion.

As pointed out earlier, our finding that the MPP has no effect on sales but a positive effect on quantities is consistent with an underlying unit elastic demand. This takes the form $p=A / q$, where $A$ is the total sales revenue obtained in the market. When at least one unit

\footnotetext{
${ }^{33}$ This led some advocacy groups, such as the Initiative for Medicines, Access, and Knowledge (I-MAK), to voice concerns after the 2011 MPP-Gilead agreement because it appeared too similar to existing Gilead's licenses. Source: www.i-mak.org/2011/10/11/implications-of-the-patent-pool-licenses-with-gilead-part-ii/

${ }^{34}$ Specifically, we regress the variable capturing launch by a licensee on Access and its interaction with MPP including year and product-country effects. The estimates show a positive correlation between Access and launch which is reduced substantially once the product-country is included in the MPP.
} 
of product is consumed, the corresponding total welfare is $W=A \log (q)$, which implies that an increase in quantity by $z$ percent translates to a welfare gain of $A z / 100$. In principle, we can use this demand function to perform a 'back of the envelope' calculation of the welfare gains from the MPP. For this, we need to know the sales generated by a drug five years after it enters the pool and use our parameter estimates of the MPP impact on volume to compute the welfare generated by each drug licensed by the MPP. A full welfare analysis along these lines is not feasible with our data, as many of the countries that are listed in MPP licenses are not in the IQVIA sales data. Moreover, many of the MPP licenses in our data are less than five years old, so these estimates can be only be done for a very limited set of drugs.

Nonetheless, we do this calculation on the available data, but we emphasize that it represents an extreme lower bound for the reasons mentioned. To perform this computation we identified the product-countries in which MPP licenses were in place for more than 5 years and for which positive sales were recorded by IQVIA. We used the average revenue generated in the sample years following the fourth after MPP inclusion as a proxy for the demand scale parameter, $A$. The increase in quantity is obtained by exponentiating the coefficient estimated in column 5 of Table 7 (61 percent), and we assume this increase in volume lasts until the patent expires in the focal country. We compute a welfare gain of roughly 27 million USD for the period 2010-18. By comparison, the total operating costs of the MPP for the period 2010-2015 was 22.9 million USD (Junejia et al., 2017). Given that the computed welfare gains are almost certainly a substantial underestimate, even this simple exercise suggests that the welfare benefits from the MPP well exceed the cost of the institution.

\section{Conclusions}

In this paper we examine how the Medicines Patent Pool affects licensing and launch of HIV and other essential drugs in low- and middle-income countries. There are three key empirical findings. First, inclusion in the pool is associated with a five-fold increase in the probability of licensing. Second, the effect is heterogeneous -it is much larger for small, non-sub-Saharan countries and smaller in countries with large exposure to HIV (where bilateral deals are more likely). Finally, we show that being in the MPP has real impacts on product market outcomes - increasing the likelihood of launch, increasing quantities sold and reducing prices. The magnitude of these effects is much smaller than the one estimated for the effect on licensing. We argue that this differential effect is driven by the bundled nature of the pool license contracts 
and by a lower propensity of patentees to be active in a country once a product enters the MPP.

Our analysis highlights that, in order to study the impact of patent pools with geographical bundling on technology diffusion, it is important to go beyond their impact on licensing. Focusing exclusively on licensing is likely to overstate the impact of the pool on actual market diffusion. This is both because the licensee is typically not going to launch in all countries in the bundled license and because the patentee may be less likely to be active in the country when the product is covered by the pool. More broadly, our paper suggests the potential of pools to promote diffusion of other types of innovation in developing countries, including climate mitigation technologies. 


\section{References}

[1] Bolton, Patrick, and Joseph Farrell (1990) "Decentralization, duplication, and delay," Journal of Political Economy 98: 803-826.

[2] Branigan, David (2018), "Key Hepatitis C Drug Licensed To Medicines Patent Pool, Access Expanded For LMICs," Intellectual Property Watch, November 12

[3] Cockburn, Iain, Jean Lanjouw, and Mark Schankerman (2016) "Patents and the global diffusion of new drugs," American Economic Review 106: 136-64

[4] Delgado, Mercedes, Margaret Kyle and Anita McGahan (2013) "Intellectual property protection and the geography of trade," Journal of Industrial Economics 61: 733-762

[5] Dubois, Pierre, Yassine Lefouili and Stéphane Straub (2021) "Pooled Procurement of Drugs in Low and Middle Income Countries," European Economic Review 132: 1-23

[6] Duggan, Mark, Craig Garthwaite and Aparajita Goyal (2016) "The market impacts of pharmaceutical product patents in developing countries: Evidence from India," American Economic Review 106: 99-135

[7] Furman, Jeffrey and Scott Stern (2011) "Climbing atop the shoulders of giants: The impact of institutions on cumulative research," American Economic Review 101: 1933-63

[8] Galasso, Alberto and Mark Schankerman (2015) "Patents and Cumulative Innovation: Causal Evidence from the Courts," Quarterly Journal of Economics 130: 317-369

[9] Gans, Joshua (2020), Economics in the Age of COVID-19 (Cambridge, MA: MIT Press).

[10] Greenstone, Michael, Richard Hornbeck and Enrico Moretti (2010), "Identifying agglomeration spillovers: Evidence from winners and losers of large plant openings," Journal of Political Economy 118: 536-598

[11] Gokengin, Deniz, Cristiana Oprea, Josip Begovac, Andrzej Horban, Arzu Nazlı Zeka, Dalibor Sedlacek Bayjanov Allabergan et al. (2018), "HIV care in Central and Eastern Europe: How close are we to the target?," International Journal of Infectious Diseases 70: $121-130$

[12] Hong, Harrison and Inessa Liskovich (2015) "Crime, punishment and the halo effect of corporate social responsibility," National Bureau of Economic Research, Working Paper 21215

[13] Juneja, Sandeep, Aastha Gupta, Suerie Moon and Stephen Resch (2017), "Projected savings through public health voluntary licences of HIV drugs negotiated by the Medicines Patent Pool (MPP)," PloS one 12: e0177770 
[14] Kennedy, Nick (2015) "Merck's HIV patent agreement ignites criticism," SciDevNet, 13 March, available at www.scidev.net/global/news/merck-hiv-patent-agreement-monopolycriticism/

[15] Kyle, Margaret (2006) "The role of firm characteristics in pharmaceutical product launches," RAND Journal of Economics 37: 602-618

[16] Kyle, Margaret (2007) "Pharmaceutical price controls and entry strategies," Review of Economics and Statistics 89: 88-99

[17] Kremer, Michael and Christopher Snyder (2015), "Preventives versus treatments," Quarterly Journal of Economics 130: 1167-1239

[18] Kremer, Michael and Christopher Snyder (2018), "Preventives versus treatments redux: Tighter bounds on distortions in innovation incentives with an application to the global demand for HIV pharmaceuticals," Review of Industrial Organization 53: 235-273

[19] Lampe, Ryan, and Petra Moser (2013) "Patent pools and innovation in substitute technologies - evidence from the 19th-century sewing machine industry," RAND Journal of Economics 44: 757-778

[20] Lampe, Ryan, and Petra Moser (2015) "Patent pools, competition, and innovationEvidence from 20 US industries under the New Deal," Journal of Law, Economics, and Organization 32: 1-36

[21] Layne-Farrar, Anne and Josh Lerner (2011) "To join or not to join: Examining patent pool participation and rent sharing rules," International Journal of Industrial Organization 29: 294-303

[22] Lee, David and Thomas Lemieux (2010), "Regression discontinuity designs in economics," Journal of Economic Literature 48.2: 281-355

[23] Lemley, Mark and Timothy Simcoe (2018), "How essential are standard-essential patents," Cornell Law Review 104: 607-637

[24] Lerner, Josh and Jean Tirole (2004) "Efficient patent pools," American Economic Review 94: $691-711$

[25] Lerner, Josh, Marcin Strojwas, and Jean Tirole (2007) "The design of patent pools: The determinants of licensing rules" RAND Journal of Economics 38: 610-625

[26] Llanes, Gaston and Joaquin Poblete (2014) "Ex-Ante Agreements in Standard Setting And Patent-Pool Formation," Journal of Economics and Management Strategy 23: 50-67

[27] Martinelli, Arianna, Andrea Mina and Elena Romito (2020) "Collective licensing and asymmetric information: The double effect of the Medicine Patent Pool on generic drug markets," Scuola Superiore Sant'Anna working paper 
[28] Medicines Patent Pool (2018), "Exploring the Expansion of the Medicines Patent Pool's Mandate to Patented Essential Medicines: A Feasibility Study of the Public Health Needs and Potential Impact," MPP Publications

[29] Merges, Robert. (2001) "Institutions for Intellectual Property Transactions: The Case of Patent Pools," in R. Dreyfuss, D. Zimmerman, and H. First, eds., Expanding the Boundaries of Intellectual Property. (Oxford, UK: Oxford University Press)

[30] Quint, Daniel (2014) "Pooling with Essential and Nonessential Patents," American Economic Journal: Microeconomics 6: 23-57

[31] Reisinger, Markus and Emanuele Tarantino (2019) "Patent pools, vertical integration, and downstream competition," RAND Journal of Economics 50: 168-200

[32] Van Zimmeren, Esther, Sven Vanneste, Gert Matthijs, Wim Vanhaverbeke, and Geertrui Van Overwalle (2011) "Patent pools and clearinghouses in the life sciences," Trends in Biotechnology 29: 569-576

[33] Wang, Lucy Xiaolu (2020) "Global drug diffusion and innovation with a patent pool: The case of HIV drug cocktails," Max Planck Institute for Innovation and Competition, Working Paper

[34] Williams, Heidi (2013) "Intellectual property rights and innovation: Evidence from the human genome," Journal of Political Economy 121: 1-27

[35] Sampat, Bhaven and Heidi Williams (2019) "How do patents affect follow-on innovation? Evidence from the human genome," American Economic Review 109: 203-36 
FIGURE 1: Differences in MPP inclusion for lower middle-income and upper middle-income countries

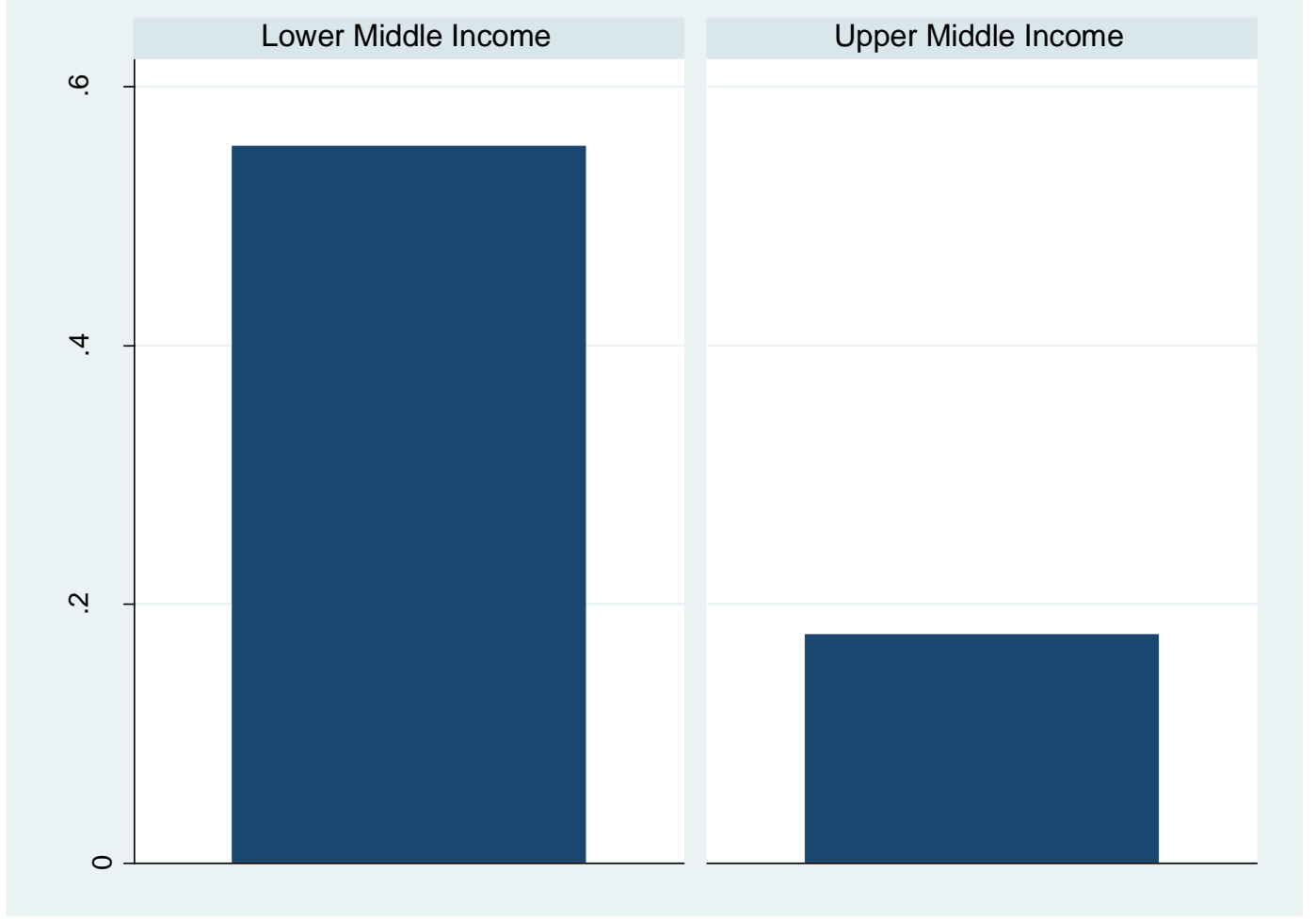

NOTES: The sample includes 108 product-country observations for countries that were within 500 dollars from the threshold for the upper middle-income World Bank classification in the year in which the drug entered the MPP. 
Table 1 - Panel A: Summary Statistics

\begin{tabular}{lccccc}
\hline & obs. & mean & sd & min & max \\
\hline Access & 80,103 & 0.180 & 0.385 & 0 & 1 \\
Deals & 14,453 & 4.589 & 4.365 & 1 & 20 \\
MPP sublicenses & 14,453 & 1.408 & 2.801 & 0 & 17 \\
Bilateral deals & 14,453 & 3.181 & 3.609 & 0 & 13 \\
& & & & & \\
\hline
\end{tabular}

Panel B: Mean comparisons for MPP inclusion

\begin{tabular}{lccc}
\hline & obs. & Access & Deals \\
& & & \\
\hline & & 0.133 & 0.481 \\
$\begin{array}{l}\text { Product-countries never } \\
\text { in MPP }\end{array}$ & 65,886 & $(0.339)$ & $(1.842)$ \\
& & & \\
$\begin{array}{l}\text { MPP product-countries } \\
\text { before entry }\end{array}$ & 8,588 & 0.092 & 0.454 \\
& & $(0.290)$ & $(1.857)$ \\
$\begin{array}{l}\text { MPP product-countries } \\
\text { after entry }\end{array}$ & 5,629 & 0.870 & 5.454 \\
& & $(0.335)$ & $(5.021)$ \\
\hline
\end{tabular}

NOTES: Unit of observation is product-country-year. In panel A the statistics for Deals, MPP sublicenses and Bilateral deals are restricted to the sample in which Access $=1$. In panel $B$ standard deviations are in parentheses. 
Table 2: MPP, access and licensing deals

\begin{tabular}{|c|c|c|c|c|c|}
\hline & (1) & (2) & (3) & (4) & (5) \\
\hline Dep. Var. & Access & Deals & Access & Deals & Deals \\
\hline MPP & $\begin{array}{c}0.663^{* * *} \\
(0.010)\end{array}$ & $\begin{array}{c}4.610^{* * *} \\
(0.113)\end{array}$ & & & \\
\hline MPP year 1 & & & $\begin{array}{c}0.384^{* * *} \\
(0.022)\end{array}$ & $\begin{array}{c}1.259 * * * \\
(0.072)\end{array}$ & $\begin{array}{c}1.242^{* * *} \\
(0.072)\end{array}$ \\
\hline MPP year 2 & & & $\begin{array}{c}0.453^{* * *} \\
(0.022)\end{array}$ & $\begin{array}{c}1.312^{* * *} \\
(0.079)\end{array}$ & $\begin{array}{c}1.295^{* * *} \\
(0.081)\end{array}$ \\
\hline MPP year 3 & & & $\begin{array}{c}0.456 * * * \\
(0.022)\end{array}$ & $\begin{array}{c}1.362^{* * *} \\
(0.081)\end{array}$ & $\begin{array}{c}1.346^{* * *} \\
(0.082)\end{array}$ \\
\hline MPP year 4 & & & $\begin{array}{c}0.532^{* * *} \\
(0.021)\end{array}$ & $\begin{array}{c}1.835^{* * *} \\
(0.103)\end{array}$ & $\begin{array}{c}1.818^{* * *} \\
(0.103)\end{array}$ \\
\hline MPP years $5+$ & & & $\begin{array}{c}0.667^{* * *} \\
(0.014)\end{array}$ & $\begin{array}{c}4.419 * * * \\
(0.134)\end{array}$ & $\begin{array}{c}4.402^{* * *} \\
(0.133)\end{array}$ \\
\hline MPP year -1 & & & & & $\begin{array}{l}-0.051 \\
(0.032)\end{array}$ \\
\hline MPP year -2 & & & & & $\begin{array}{l}-0.046 \\
(0.031)\end{array}$ \\
\hline Year effects & YES & YES & YES & YES & YES \\
\hline Product-country effects & YES & YES & YES & YES & YES \\
\hline Observations & 80103 & 80103 & 72693 & 72693 & 72693 \\
\hline
\end{tabular}


Table 3: Effect of MPP for drugs in the 2010 priority list

\begin{tabular}{|c|c|c|c|c|c|}
\hline & (1) & (2) & (3) & (4) & (5) \\
\hline Dep. Var. & Access & Deals & Access & Deals & Deals \\
\hline MPP & $\begin{array}{c}0.603 * * * \\
(0.055)\end{array}$ & $\begin{array}{c}3.083^{* * *} \\
(0.617)\end{array}$ & $\begin{array}{c}0.589 * * * \\
(0.055)\end{array}$ & $\begin{array}{c}3.046^{* * *} \\
(0.615)\end{array}$ & $\begin{array}{c}3.023 * * * \\
(0.621)\end{array}$ \\
\hline MPP year -1 & & & & & $\begin{array}{l}-0.105 \\
(0.088)\end{array}$ \\
\hline MPP year -2 & & & & & $\begin{array}{l}-0.027 \\
(0.085)\end{array}$ \\
\hline Sample & $\begin{array}{c}2010 \text { priority } \\
\text { list }\end{array}$ & $\begin{array}{c}2010 \text { priority } \\
\text { list }\end{array}$ & $\begin{array}{c}2010 \text { priority } \\
\text { list without } \\
\text { etravirine }\end{array}$ & $\begin{array}{c}2010 \\
\text { priority list } \\
\text { without } \\
\text { etravirine }\end{array}$ & $\begin{array}{c}2010 \\
\text { priority list } \\
\text { without } \\
\text { etravirine }\end{array}$ \\
\hline Observations & 40536 & 40536 & 38136 & 38136 & 38136 \\
\hline
\end{tabular}




\section{Table 4: Controlling for country characteristics}

\begin{tabular}{|c|c|c|c|c|c|c|}
\hline & (1) & $(2)$ & (3) & (4) & (5) & (6) \\
\hline Dep. Var. & Access & Deals & Access & Deals & Access & Deals \\
\hline MPP & $\begin{array}{c}0.623^{* * *} \\
(0.011)\end{array}$ & $\begin{array}{c}4.421^{* * *} \\
(0.114)\end{array}$ & $\begin{array}{c}0.559 * * * \\
(0.014)\end{array}$ & $\begin{array}{c}2.365^{* * *} \\
(0.081)\end{array}$ & $\begin{array}{c}0.530 * * * \\
(0.012)\end{array}$ & $\begin{array}{c}3.845^{* * *} \\
(0.115)\end{array}$ \\
\hline $\log$ (Population) & $\begin{array}{c}1.214^{* * *} \\
(0.050)\end{array}$ & $\begin{array}{c}5.005^{* * *} \\
(0.286)\end{array}$ & $\begin{array}{c}1.544^{* * *} \\
(0.062)\end{array}$ & $\begin{array}{c}4.588^{* * *} \\
(0.252)\end{array}$ & & \\
\hline Perc. Pop. HIV & & & $\begin{array}{c}0.050 * * * \\
(0.010)\end{array}$ & $\begin{array}{c}0.186 * * * \\
(0.042)\end{array}$ & & \\
\hline Health Exp. & & & $\begin{array}{c}0.014^{* *} \\
(0.007)\end{array}$ & $\begin{array}{c}0.040 \\
(0.037)\end{array}$ & & \\
\hline Country-year effects & NO & NO & NO & NO & YES & YES \\
\hline Year effects & YES & YES & YES & YES & YES & YES \\
\hline Product-country effects & YES & YES & YES & YES & YES & YES \\
\hline Observations & 78498 & 78498 & 54734 & 54734 & 80103 & 80103 \\
\hline
\end{tabular}




\section{Table 5: World Bank status and MPP effect}

(1)

Deals 3 yrs

$5.365^{* * *}$

$(0.440)$
(2)

MPP

(3)

Deals 3 yrs

Deals 3 yrs

MPP

Upper Middle-Income

Sample

Estimation

First stage F-stat

Observations
OLS

OLS - 1st stage

15 percentiles $\quad 15$ percentiles above/below upper above/below upper middle-income threshold middle-income threshold

(0.049)
(4)

$11.198^{* * *}$

(3.086)
$6.403 * * *$

(1.291)
15 percentiles above/below upper middleincome threshold income threshold

NOTES: standard errors clustered at the product-country level in parentheses. ${ }^{*} p<0.10,{ }^{* *} p<0.05,{ }^{* * *} p<0.01$. Deals 3 years= total number of licensing deals for the country product in the three years following MPP inclusion. Upper Middle-Income $=1$ if country classified as upper middle-income by the World Bank. MPP $=1$ if the productcountry is included in an upstream MPP license. Columns 3 and 4 instrument MPP with the dummy Upper MiddleIncome. The sample is a cross-section and only includes medicines that enter the MPP. 


\section{Table 6: Heterogeneous effects}

\begin{tabular}{|c|c|c|c|c|c|c|}
\hline & (1) & $(2)$ & (3) & (4) & (5) & (6) \\
\hline Dep. Var. & Access & Access & Access & Deals & Deals & Deals \\
\hline MPP & $\begin{array}{c}0.663^{* * *} \\
(0.011)\end{array}$ & $\begin{array}{c}0.552^{* * *} \\
(0.015)\end{array}$ & $\begin{array}{c}0.517^{* * *} \\
(0.014)\end{array}$ & $\begin{array}{c}4.584^{* * *} \\
(0.129)\end{array}$ & $\begin{array}{c}2.340 * * * \\
(0.089)\end{array}$ & $\begin{array}{c}3.862^{* * *} \\
(0.130)\end{array}$ \\
\hline MPP x Top HIV & $\begin{array}{c}-0.082 * * \\
(0.038)\end{array}$ & $\begin{array}{c}-0.125^{* * *} \\
(0.044)\end{array}$ & $\begin{array}{c}-0.096 * * \\
(0.048)\end{array}$ & $\begin{array}{c}-0.121 \\
(0.359)\end{array}$ & $\begin{array}{c}0.050 \\
(0.255)\end{array}$ & $\begin{array}{l}0.041 \\
(0.382)\end{array}$ \\
\hline MPP $x$ Small not Sub-Saharan & $\begin{array}{l}0.040^{*} \\
(0.023)\end{array}$ & $\begin{array}{c}0.177^{* * *} \\
(0.042)\end{array}$ & $\begin{array}{c}0.146 * * * \\
(0.033)\end{array}$ & $\begin{array}{c}0.235 \\
(0.323)\end{array}$ & $\begin{array}{c}0.188 \\
(0.269)\end{array}$ & $\begin{array}{l}-0.143 \\
(0.342)\end{array}$ \\
\hline Demographic controls & NO & YES & NO & NO & YES & NO \\
\hline Country-year effects & NO & NO & YES & NO & NO & YES \\
\hline Year effects & YES & YES & YES & YES & YES & YES \\
\hline Product-country effects & YES & YES & YES & YES & YES & YES \\
\hline Observations & 80103 & 54734 & 80103 & 80103 & 54734 & 80103 \\
\hline
\end{tabular}




\section{Table 7: MPP and market outcomes}

\begin{tabular}{|c|c|c|c|c|c|}
\hline & (1) & $(2)$ & (3) & (4) & (5) \\
\hline Dep. Var. & one firm & $\begin{array}{c}\text { one } \\
\text { licensee }\end{array}$ & patentee & $\log ($ sales) & log(volume) \\
\hline MPP up to year 4 & $\begin{array}{c}-0.051^{* *} \\
(0.023)\end{array}$ & $\begin{array}{c}0.003 \\
(0.019)\end{array}$ & $\begin{array}{c}-0.068^{* * *} \\
(0.014)\end{array}$ & $\begin{array}{l}-0.009 \\
(0.073)\end{array}$ & $\begin{array}{c}0.155 \\
(0.137)\end{array}$ \\
\hline MPP years $5+$ & $\begin{array}{l}-0.038 \\
(0.037)\end{array}$ & $\begin{array}{l}0.076^{*} \\
(0.041)\end{array}$ & $\begin{array}{c}-0.090 * * * \\
(0.031)\end{array}$ & $\begin{array}{c}0.190 \\
(0.159)\end{array}$ & $\begin{array}{c}0.476 * * \\
(0.195)\end{array}$ \\
\hline Year effects & YES & YES & YES & YES & YES \\
\hline Product-country effects & YES & YES & YES & YES & YES \\
\hline Observations & 24663 & 24663 & 24663 & 24663 & 24663 \\
\hline
\end{tabular}




\section{APPENDIX FIGURES AND TABLES}

Figure A1: Access before and after the establishment of MPP

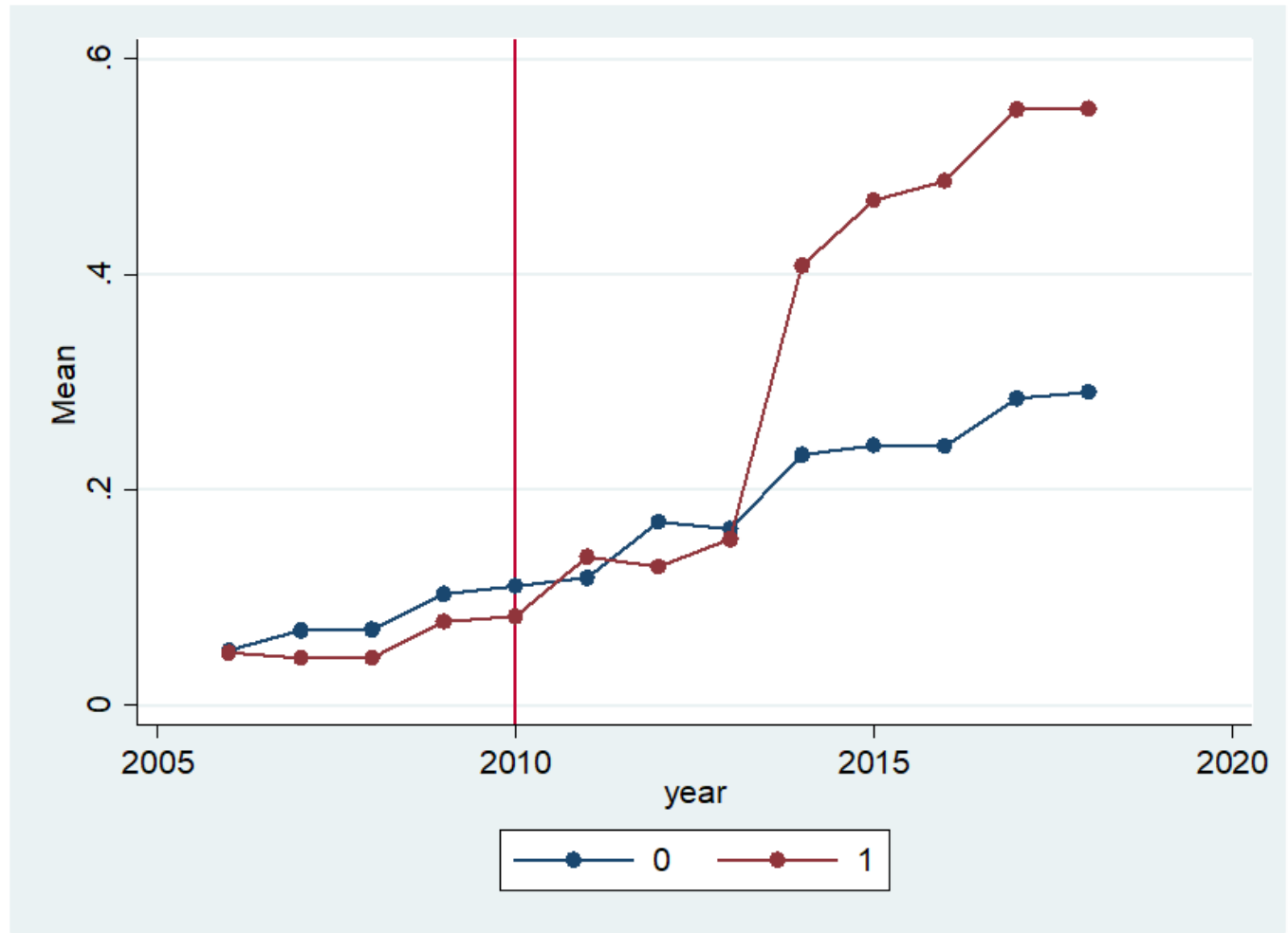

NOTES: The figure plots the trend in Access distinguishing between products that enter in the MPP by 2018 (1, red line) and products that do not enter the MPP (0, blue line). 


\section{Table A1: Robustness to alternative econometric models}

\begin{tabular}{|c|c|c|c|c|c|}
\hline & (1) & (2) & (3) & (4) & (5) \\
\hline Dep. Var. & Deals & Deals & $\log ($ Deals+1) & new Deals & first Access \\
\hline MPP & $\begin{array}{c}1.552 * * * \\
(0.122)\end{array}$ & $\begin{array}{c}1.920 * * * \\
(0.035)\end{array}$ & $\begin{array}{c}1.251^{* * *} \\
(0.022)\end{array}$ & $\begin{array}{c}1.709 * * * \\
(0.046)\end{array}$ & $\begin{array}{c}0.153^{* * *} \\
(0.004)\end{array}$ \\
\hline Estimation & Poisson & Neg. Bin. & OLS & OLS & OLS \\
\hline Observations & 29183 & 29183 & 80103 & 80103 & 80103 \\
\hline
\end{tabular}




\section{Table A2: Deals extension, imputation and molecule level analysis}

\begin{tabular}{|c|c|c|c|c|c|c|}
\hline & (1) & (2) & (3) & (4) & (5) & (6) \\
\hline Dep. Var. & Access & Deals & Deals & Deals & Access & Deals \\
\hline MPP & $\begin{array}{c}0.653 * * * \\
(0.011)\end{array}$ & $\begin{array}{c}4.508^{* * *} \\
(0.117)\end{array}$ & $\begin{array}{c}4.615^{* * *} \\
(0.113)\end{array}$ & $\begin{array}{c}4.916 * * * \\
(0.116)\end{array}$ & $\begin{array}{c}0.677^{* * *} \\
(0.021)\end{array}$ & $\begin{array}{c}4.529 * * * \\
(0.223)\end{array}$ \\
\hline Imputed deals & & & $\begin{array}{c}-0.131 * * \\
(0.064)\end{array}$ & & & \\
\hline Notes & $\begin{array}{l}\text { drop deal } \\
\text { extensions }\end{array}$ & $\begin{array}{l}\text { drop deal } \\
\text { extensions }\end{array}$ & full sample & $\begin{array}{l}\text { drop } \\
\text { imputed } \\
\text { deals }\end{array}$ & $\begin{array}{c}\text { molecule- } \\
\text { country } \\
\text { aggregation }\end{array}$ & $\begin{array}{c}\text { molecule- } \\
\text { country } \\
\text { aggregation }\end{array}$ \\
\hline Observations & 77817 & 77817 & 80103 & 77867 & 18639 & 18639 \\
\hline \multicolumn{7}{|c|}{$\begin{array}{l}\text { NOTES: standard errors clustered at the product-country level in parenthesis. }{ }^{*} p<0.10,{ }^{* *} p<0.05,{ }^{* * *} p< \\
0.01 \text {. Deals= total number of licensing deals for the country product in year } \mathrm{t} \text { (includes MPP and non-MPP } \\
\text { deals). Access }=1 \text { if Deals }>0 . \text { MPP }=1 \text { if the product-country is included in an upstream MPP license. Imputed } \\
\text { deals }=1 \text { if information on bilateral deals is incomplete. Columns } 1 \text { and } 2 \text { drop product countries that enter } \\
\text { MPP through revisions of existing deals. In columns } 5 \text { and } 6 \text { the data are aggregated at the molecule-country } \\
\text { level with standard errors clustered at the same level. Product combinations dropped from the sample in } \\
\text { columns } 5 \text { and } 6 \text {. }\end{array}$} \\
\hline
\end{tabular}


Table A3: World Bank classification and MPP - Robustness

Dep. Var.

MPP

Demographic controls

Sample

First stage F-stat

Observations
(1)

$(2)$

(3)

Deals 5 yrs

$7.597^{* * *}$

NO

NO
(4)

Deals 5 yrs

$13.011 * * *$

(3.611)

Deals 3 yrs

Access 3 yrs

$6.913 * * *$

(1.469)

$0.925^{* * *}$

(0.092)

YES

NO
Products in 2010 priority list and countries within

\section{5 percentiles}

above/below upper middle-income threshold

\author{
15 percentiles \\ above/below upper \\ middle-income \\ threshold \\ $\$ 500$ above/below \\ upper middle- \\ income threshold
}

15 percentiles above/below upper middle-

NOTES: standard errors clustered at the product-country level in parentheses. ${ }^{*} p<0.10,{ }^{* *} p<0.05,{ }^{* * *} p<0.01$. Deals 3 (5) years $=$ total number of licensing deals for the country product in the 3 (5) years following MPP inclusion. Regressions instrument MPP with the dummy Upper MiddleIncome. The sample is a cross-section and columns 2-5 only include medicines that enter the MPP. Demographic controls include log(Population), percentage of population with HIV and health expenditure per capita. Access $3=1$ if at least one deal in the 3 years following MPP inclusion. 
Table A4: MPP and market outcomes -molecule level analysis

Dep. Var.

MPP up to year 4

MPP years $5+$

Year effects

Molecule-country effects

Observations
(1)

(2)

one firm licensee patentee

$\begin{array}{ccc}-0.089 * * & 0.058 & -0.123 * * * \\ (0.039) & (0.038) & (0.026)\end{array}$

$-0.061$

$0.159 * *$

$-0.168 * *$

$(0.102)$

(0.062)

(0.081)

$\begin{array}{lll}\text { YES } & \text { YES } & \text { YES } \\ \text { YES } & \text { YES } & \text { YES }\end{array}$

$10842 \quad 10842 \quad 10842$

NOTES: standard errors clustered at the molecule-country level in parentheses. ${ }^{*} \mathrm{p}<0.10,{ }^{* *} \mathrm{p}<0.05, * * * \mathrm{p}<0.01$. One firm= at least one firm has launched one product related to the molecule in the country by year $t$. One licensee $=1$ if at least one licensee has launched. Patentee $=1$ if original patentee has launched. 